\title{
ADDENDUM TO: ON EXISTENCE AND RIGIDITY OF ISO- METRIC IMMERSIONS
}

BY R. H. SZCZARBA

Communicated November 4, 1969

It has been pointed out to me that the existence theorem of [2] is a reformulation of the ambient space euclidean case of Theorem 5 , p. 202 of Bishop and Crittenden [1]. I am also told that, although not stated in [1], the rigidity theorem of [2] can be proved as a consequence of Theorem 5. Of course, the approach of [2] is quite different from that of Bishop and Crittenden. In particular, from the point of view of [2], the rigidity theorem is an easy computation.

\section{BIBLIOGRAPHY}

1. R. L. Bishop and R. J. Crittenden, Geometry of manifolds, Pure and Appl. Math., vol. 15, Academic Press, New York, 1964. MR 29 \#6401.

2. R. H. Szczarba, On existence and rigidity of isometric immersions, Bull. Amer. Math. Soc. 75 (1969), 783-787.

Yale University, New Haven, Connecticut 06520 